\section{Childhood Sexual Abuse: Sibling Perspectives}

Journal of Interpersonal Violence

$1-22$

(C) The Author(s) 2018

Reprints and permissions: sagepub.com/journalsPermissions.nav DOI: I0.1I77/08862605|8769356 journals.sagepub.com/home/jiv

(S)AGE

\author{
Elaine Crabtree,' Charlotte Wilson,' \\ and Rosaleen McElvaney ${ }^{2}$
}

\begin{abstract}
Despite a recent focus highlighting the systemic impact of childhood sexual abuse (CSA), the needs of nonabused siblings have been largely overlooked. This interpretative phenomenological analysis study explored the lived experience of nonabused adult siblings of survivors of CSA. Semistructured interviews were undertaken with five adult siblings who were, or had been attending a support service. Emergent themes demonstrated the personal and relational impact of CSA on siblings which were captured across five domains: trying to make sense of it all, struggling to provide support, managing the impact on the wider family, feeling silenced and finding a voice, and rescripting the future. Participants struggled to make sense of their sibling's experience, questioning their own memories of happy childhoods, often in the face of limited information about what happened. The impact of the sexual abuse not only affected the sibling relationship but was compounded by the distress of other family members, particularly parents. Participants reported feeling a lack of reciprocity in terms of their own support needs and described ongoing issues arising from the sexual abuse that they believed would likely continue for the rest of their lives. How siblings can be supported through psychoeducation and family therapy is discussed, both for their own needs and those of the entire family.
\end{abstract}

\title{
Keywords
}

sexual abuse, child abuse, family issues and mediators, vicarious trauma

\footnotetext{
ITrinity College Dublin, Ireland

${ }^{2}$ Dublin City University, Ireland

\section{Corresponding Author:}

Elaine Crabtree, Trinity College Dublin, Áras An Phiarsaigh, Dublin 2, Ireland.

Email: crabtree@tcd.ie
} 
The long-term consequences of childhood sexual abuse (CSA) are far reaching and extend beyond the initial victim (Elliott \& Carnes, 2001; van Toledo \& Seymour, 2013). Disclosure of CSA creates a crisis that impacts the entire family (Humphreys, 1995; Welfare, 2008); however, the experiences of nonabused siblings are almost absent from the research literature (Schreier, Pogue, \& Hansen, 2017).

Research on adult outcomes found that recovery from CSA is a process and that victim coping can change across different developmental stages (Walsh, Fortier, \& DiLillo, 2010). CSA is a risk factor for depression, anxiety, psychiatric disorders, self-harm, suicide, substance abuse, interpersonal difficulties, lower occupational achievement, domestic violence, and parenting difficulties (Maniglio, 2009). Most victims do not disclose CSA until adulthood (McElvaney, 2015). Thus, most family members may not learn about abuse for many years, if at all.

Studies assessing the adjustment of nonoffending parents following CSA disclosure can serve as a basis for understanding the perspectives of siblings. Parents may experience a range of emotions including shock and numbness, guilt and self-blame, anger toward themselves and the perpetrator, and fear and anxiety regarding the future (Han \& Kim, 2016; Humphreys, 1995; Plummer \& Eastin, 2007). Parents may become severely distressed displaying symptoms of posttraumatic stress disorder (Cyr et al., 2016; Davies, 1995) and clinical depression (Cyr et al., 2016). Family relationships may come under considerable strain, negatively affecting wider family functioning (Davies, 1995), including conflict within the marital relationship of nonoffending parents (Han \& Kim, 2016; Humphreys, 1995). The relationship between parent and child can also be impacted as parents struggle to support their child (Plummer \& Eastin, 2007). Much of the research has focused on relationships between parents and younger children. It neglects to take account of the longer term impact on family relationships between adult children and their parents. Welfare (2008) found that previously close parentchild relationships became strained following adult disclosures of CSA.

Siblings are integral members of the family system and play a key role in shaping the family environment (Cox, 2010). The absence of siblings' perspectives in the research literature is therefore noteworthy. Sibling relationships are among the longest lasting relationships of an individual's life (Cicirelli, 1995). They may buffer the negative impact of stressful life events on children (Gass, Jenkins, \& Dunn, 2007), compensate for low-level parent support, and provide protection from loneliness and depression in early adulthood (Milevsky, 2005) and old age (Cicirelli, 1989). Given that family responses and subsequent support play a part in determining victim recovery across the lifespan (for reviews, see Elliott \& Carnes, 2001; Ullman, 2003), 
sibling support may be beneficial to victims following a disclosure of CSA. Understanding the effect of CSA for siblings is important because research findings show that parents often struggle with own emotional reactions to a child's disclosure. This in turn can impact on parents' capacity to support their children (Elliott \& Carnes, 2001).

Most studies about nonabused siblings are based on clinical observations or maternal reports of child siblings (Schreier et al., 2017). As younger siblings share family environments they may be impacted by disruptions in the family (Baker, Tanis, \& Rice, 2001; Hill, 2003; Tavkar \& Hansen, 2011). Exploratory research indicates that siblings are impacted by the distress of other family members. Pogue et al. (2015) found that parental worry over parenting abilities following a disclosure of CSA was associated with higher levels of depression and anxiety in nonabused siblings. Hill (2003) noted that children's limited awareness of their sibling's abuse resulted in confusion and anxiety as they struggled to understand the changes occurring in their family (Han \& Kim, 2016; Hill, 2003; Tavkar \& Hansen, 2011). Nonabused siblings have been described as feeling isolated and betrayed following disclosure (Hill, 2003). In cases where the abuse was perpetrated by a father or close family member, siblings experienced conflicted feelings of anger, hurt, and intense loss with no space to express any positive or ambivalent feelings toward the abuser (Baker et al., 2001; Hill, 2003).

Victims receive increased attention from parents, leaving siblings feeling neglected, which may result in feelings of jealousy and resentment. Some siblings may present with increased externalizing and aggressive behaviors toward their siblings, which can lead to tensions in the parent-child relationship (Han \& Kim, 2016; Hill, 2003; Plummer \& Eastin, 2007). Dealing with the consequences of disclosure may be difficult for siblings: coping with police investigations, legal proceedings, and feelings of stigma and shame when the abuse occurred in the family (Baker et al., 2001; Hill, 2003; Tavkar $\&$ Hansen, 2011). Siblings may also experience a decline in social support as they deal with intrusive questions and may not know how to talk to friends about the abuse (Baker et al., 2001).

McElvaney (2015) found that the majority of CSA disclosures are made in adulthood. Yet to date, only one study has directly explored the impact of CSA on adult siblings. Welfare (2008) interviewed four adult siblings in a study examining family experiences of sibling perpetrated sexual abuse. She found that nonoffending siblings reported posttraumatic stress symptoms and depression associated with the disclosure. They reported feelings of intense grief and loss because their childhood memories were destroyed, forcing them to reconstruct their image of family. Relationships suffered because siblings felt torn as they tried to support the victim, the offender, and their 
parents. Some siblings disconnected from their family because they were unable to cope with the changed dynamics. Kia-Keating, Sorsoli, and Grossman (2010) and Welfare (2008) documented instances where victims of CSA first disclosed to their sibling in adulthood. Despite this, there has been very little focus on the possible needs of adult siblings following a disclosure in the literature.

Disclosure of CSA has the potential to disrupt the lives of siblings, yet their exclusion from the research literature means the needs of this population are not well understood and are at risk of being overlooked (Tavkar \& Hansen, 2011). Given the crucial role of family support in mediating the long-term outcomes, it is important to examine the experiences of siblings to determine their needs and the factors that may influence siblings' ability to provide support in the recovery from CSA.

The aim of the present study was to explore, from a phenomological perspective, adult siblings' experiences of having a sibling who was sexually abused. This study aimed to answer the questions:

What is the experience of nonabused siblings following a CSA disclosure?

What is the impact of disclosure on family relationships?

\section{Method}

This study used an interpretative phenomenological analysis (IPA) methodology. IPA is a research method that examines personal experience and ways that individuals make sense of these experiences (Smith, Flowers, \& Larkin, 2009). It recognizes the influence of the researcher in interpreting and finding meaning in participants' experiences, described as the "double hermeneutic." This methodology was deemed appropriate for this study because of the sensitive and complex nature of the topic and the gap in the research representing the voices of nonabused siblings.

\section{Participants}

Purposive sampling was used to recruit participants from a charitable organization that provides support to those affected by sexual abuse. Participants were eligible if they had a sibling who disclosed a history of CSA but had not been sexually abused themselves, had not perpetrated the abuse, and were currently or had been involved with the support agency. Therapists were briefed about the study and contacted 42 potential participants who met the inclusion criteria. Twelve potential participants expressed an interest and agreed to telephone contact by the first author. Five individuals agreed to 
participate, comprising three brothers and two sisters from three families. A sample of five was appropriate for an IPA study (Smith et al., 2009). All participants were White, Irish nationals and ranged in age from 23 to 49 years with a mean age of 37 years. Three of the participants' siblings had experienced intrafamilial abuse by a biological uncle and an uncle-in-law, while the sibling of the other two participants experienced extrafamilial abuse perpetrated by a teacher/family friend. All sibling victims delayed their disclosure until adulthood. The average time since participants first learned of their siblings' abuse was 5.2 years (range $=2-10$ years). All of the participants believed their siblings' disclosures and were involved in supporting them through their recovery.

Ethics approval was obtained prior to data collection. Participants were informed about the purpose of the study and assured that they could withdraw at any time without impacting on service provision. Immediate support was available from the participating organization for participants distressed by the interview.

\section{Data Collection and Analysis}

Semistructured interviews were conducted by the first author. Interviews lasted on average $90 \mathrm{~min}$; four participants attended two interviews. The second interview was arranged to deepen the exploration of experiences discussed in the first interview. One participant could not attend a second interview because of work commitments. Four participants chose to be interviewed in the participating organization and one chose their home. Openended questions were developed based on literature and consultation with CSA clinicians. Examples are "describe what it was like for you to learn about your sibling's sexual abuse" and "tell me about your family relationships in the immediate aftermath of the disclosure of your sibling's abuse." Areas for exploration included the following: their experience of their sibling's disclosure, responses to the disclosure, and the perceived impact of their sibling's abuse on their lives and relationships. Participants were encouraged to elaborate on thoughts, feelings, events, and people connected with their experience to allow for the introduction of unanticipated material (Smith et al., 2009).

Interviews were digitally audiotaped and transcribed verbatim by the first author. Detailed analysis of transcripts was performed using IPA methods as outlined by Smith et al. (2009). The first author listened to and read the transcripts several times to increase familiarity with the data. Descriptive, linguistic, and conceptual comments were made on the transcripts, which represented emergent themes. Tables of emergent themes were created for each individual 
by grouping similar themes and examining and clustering these into superordinate themes that represented meaning at increasingly abstract levels. Crosscase analysis was conducted by comparing themes across participants and identifying convergence and divergence across cases until a set of master themes for the group was produced. Relevant verbatim quotes for each master theme were identified. Theme labels arose from participants' words, some of which were developed by the research team to more fully represent the overarching theme. Lack of transparency in the interpretive process was addressed through (a) returning to the analysis several times to review and alter themes and ensure that interpretation was grounded in the transcripts; (b) the use of a reflexive journal to note thoughts, impressions of interviews, and the subsequent analysis process; and (c) scrutiny and verification of themes through in-depth discussion in supervision with the second and third authors.

\section{Results}

Participants described living with the consequences of abuse long before they were even aware of it. The initial disclosure represented a long and painful journey that affected their past view of their family life, their present relationships, and their view of the future. Participants navigated changes in their relationships with their siblings, disruptions to their wider family dynamics, the ongoing need to provide support to their sibling and other family members, and new issues continuously stemming from the abuse. Five domains emerged from the interviews: trying to make sense of it all, struggling to provide support, managing the impact on the wider family, feeling silenced and finding a voice, and rescripting the future. Each domain is illustrated with quotes using pseudonyms to maintain anonymity.

\section{Trying to Make Sense of It All}

The findings highlighted participants' continuing struggle to make sense of their sibling's CSA, their struggle to process their initial reactions to disclosure, and their struggle to determine the fit of this new information with their personal narrative. "Making sense" was an ongoing and complex process that involved feeling derailed and disorientated as participants discovered additional information. Participants also had a sense that this new information helped them to make sense of their previously held beliefs about their siblings.

Participants reported feelings of shock and disbelief and many felt unable to initially process the information. Most reported engaging in avoidance or emotional numbing to cope. Participants engrossed themselves in work, cared for their family, or turned to alcohol. Some siblings experienced 
difficulties following the disclosure such as problems with concentrating; ruminating over details of the abuse and replaying events from the past; changes in sleep and appetite patterns; feeling overwhelmed by intense anger, sadness, and guilt; and panic attacks:

I would have imagined what was happening. Not so much physically what was happening, just I was imagining how afraid she would have been or whatever. That killed me, just, a child like that, just the sheer terror and her wondering, "Why is nobody coming to stop this?" you know? That haunted me. (Brendan, aged 41 years)

Participants described feeling simultaneously shocked and not shocked by the disclosure. They reported that their siblings had experienced mental health problems and acting out behaviors. Some participants tried to get help for their sibling. Others experienced anger regarding their sibling's behavior and difficulties in their relationships:

Before I knew about the abuse, I was very annoyed with her, I didn't want to talk to her. She was treating me badly and I was like, I don't need this torment, I haven't done anything to deserve this. (Michael, aged 24 years)

Following the disclosure, their siblings' mental health difficulties and confusing behavior began to make sense as they realized that they had been witnessing the long-term impact of CSA:

She was an alcoholic. That was kind of the answer, I think that was the answer to that. I suppose there's always a trigger or something isn't there ... couldn't believe it. But I could believe it, it made sense then. (Brendan, aged 41 years)

Brendan went on to describe the intense guilt he felt for his anger toward his sister, while Michael's new understanding helped him to forgive his sister and re-establish their relationship.

Participants described their sibling's initial disclosure as vague, such as "he did things to me." Most participants inferred that their sibling referred to CSA, "you were supposed to join the dots yourself" (Rebecca, aged 49 years). After their assumptions were confirmed, they had no details such as the age of their sibling when the abuse took place or the severity of the abuse. Some participants reported that this information was important to avoid minimizing what their sibling had endured:

I think it's important to use labels because if you don't put the name on it . . if you don't use those terms then I feel like you're not fully processing and going through what it is. You're still in a bit of denial going "Oh well it wasn't as bad 
as you made it out to be," that you don't want to fully acknowledge the extent that it happened. (Michael, aged 24 years)

When the perpetrator was a member of the family, participants were concerned about falsely accusing the person. Rebecca (aged 49 years) described her reluctance to label her uncle a rapist without knowing details of what had happened. Other participants did not wish to know additional details as they found it too distressing:

Part of me's like-I'd really like to know so I know how to help. Then the other part of me's like - I really don't want to know cos if, if I know then, then that's stuff I can't just forget either. (Robert, aged 28 years)

All participants perceived their childhoods as happy and "normal"; however, the disclosure forced them to reevaluate this image. There was a sense of loss as participants felt that their image of childhood was shattered, "It kind of infects it or something you know what I mean? It's like a colorful picture and someone comes and squirts black ink on it" (Brendan aged 41 years). For many participants, their sense of reality was brought into doubt as the disclosure imposed a new lens through which they had to view their childhood, "I grew up with this image in my head of, this is how my childhood was, and now that's gone. It's just making me so uncertain of what was true" (Michael, aged 24 years). Participants described development of a new narrative that incorporated their sibling's abuse. Lack of details meant that every childhood memory was uncertain. Participants wondered whether their sibling was being abused at that time. They examined the past from the perspective of adult maturity. Some participants reported that their sibling felt that they should have known about the abuse, while others expected to have known about it. Participants often had to remind themselves and/or their sibling that they were also only children at the time, Robert (aged 28 years) explained,

Being the oldest sibling, if there was something I could've done, I should have known . . . however if I was speaking objectively there's nothing I could've done because I didn't know, and, and it's very hard to, you can't help something you didn't know.

\section{Struggling to Provide Support}

All participants felt that the disclosure of CSA impacted on their relationship with their sibling. Despite believing the disclosure and commitment to the recovery process, all participants struggled to support their sibling. They also 
struggled to balance the demands and responsibilities of their own lives with the continuous need to support their sibling and other family members.

All participants reported feelings of underlying tension in their relationship with their sibling following the disclosure. Many described their sibling as temperamental and easily upset. Participants needed to monitor what they said for fear of triggering a memory of the abuse or a change in mood, "She has changed yeah. Cos she's not the, it's not that she's not the happy person that she used to be or whatever. But I think it's just there's a lot more triggers there than there used to be" (Robert, aged 28 years). Many expressed fear of upsetting their sibling by talking about the abuse, while they were afraid to be perceived as ignoring the situation. Participants reported feeling that their relationship had become strained, either due to their own feelings of uncertainty or because of ensuing family difficulties that occurred in the intervening years since the disclosure. Two male participants reported that they overcame their initial difficulties and were closer to their sister as a result. The remaining three participants felt that their relationship with their sibling had deteriorated, "she is just so hard to deal with, I suppose, that it's kind of, it's impossible to be that close to her." (Brendan, aged 41 years)

Some participants felt that their siblings' expectations of support were unclear or unrealistic. They were unsure of what their sibling wanted from them as it seemed that no matter what they did, it was wrong. Many felt their efforts to support went unrecognized that their sibling relationship was onesided as their sibling rarely expressed concern for their problems or feelings. This led to feelings of hurt, anger, and resentment:

Every time you kind of have these conversations it ends up being the [sibling] show. And I said that, I'm not proud of it but . . . you know it always comes back to how she's feeling . . . she has to have a bit of empathy for somebody else . . . everybody has shit in their life and everybody's trying to deal with things, and it can't all be about her. (Rebecca, aged 49 years)

Some participants described their sibling as emotionally abusive toward them and/or other family members. Claire (aged 44 years) described living with cycles of violence and outbursts of aggression and described being physically assaulted her by her sister on several occasions. These participants understood this behavior as a result of the emotional impact of their sexual abuse. However, they also felt that abusive behavior was inexcusable and was not something they should be expected to endure, "sometimes I really wanted to shake [sibling], please I'm begging you ... it's not my fault, you know, stop taking it out on me!" (Claire, aged 44 years). 
All participants reported feeling overwhelmed and exhausted, while some became apathetic toward their sibling's difficulties. Participants felt they required time and space to take a break from family problems and focus on their own needs.

\section{Managing the Impact on the Wider Family}

Participants managed the "knock on effects" (Rebecca, aged 49 years and Brendan, aged 41 years) as families invariably underwent disruption and change because of their sibling's disclosure. While participants spoke of their own upset at seeing their sibling's distress because of events related to the abuse, they described how much harder it had been to witness other family members' distress. Other family members experienced depression, premature aging, and physical illness. Participants reported that worrying about family members' distress exacerbated and perpetuated their own emotional difficulties:

There's always one of us it's affecting . . . it's kind of a real disappointment if you get the phone call or, you know you could be in a good mood or whatever, and then my Da might go "I didn't sleep a wink last night" and it's kind of selfish but I think, ah bollix not again. Then I feel guilty for thinking that. (Brendan, aged 41 years)

All participants lost a sense of connection with their family following the disclosure. Two participants (whose uncle was the alleged abuser) lost contact with their aunt and cousins. For one, this loss was significant as his aunt and uncle had played a formative role in his life. Another participant described how her sister no longer spoke to her mother and as a result, they could no longer be in the same room. Two participants spoke about how the disclosure, and the subsequent deterioration in their sister's mental health, had "ruined" their family. Conflict arose regarding the handling of issues related to the abuse. They felt they could no longer enjoy coming together as a family to celebrate important occasions; Claire (44) explained, "I don't think anyone realizes how much our family's changed completely. Completely. Since that that day it will never be the same again."

Participants described how trying to see issues from the perspectives of multiple family members often left them feeling confused and conflicted. Despite disagreeing, with their family's responses at times, they recognized the reasoning and motives behind each family members' actions. Participants described arbitrating during family disagreements which was exasperating, as Michael (aged 24 years) described, "I have had to play referee." Some participants described feeling torn between supporting their sibling and 
supporting their parents. This created a great deal of stress as Rebecca (49) explained, "You're making bits of yourself trying to do the right thing."

\section{Feeling Silenced and Finding a Voice}

All participants reported feeling silenced. In some cases, they internalized their difficulties for fear of burdening others. Participants felt that their sibling, other family members, and people in general did not recognize the emotional impact of the CSA on them as siblings. They felt on the periphery, and didn't know their role or place, as Michael (age 24) explained, "It kind of frustrates that me that everyone else's lives diminished, and it's not trying to diminish the importance of the abuse, but it kind of diminishes everyone else's importance." Participants also found it difficult to seek their own support because they felt they had no right to discuss the disclosure with others. Some participants felt silenced by wider culture and societal attitudes toward abuse, and they felt that CSA was a "taboo topic" that no one wanted to discuss. Other participants felt that they were being silenced by the justice system through the mishandling of their siblings' legal case.

Participants found a voice and expressed their feelings about the abuse in different ways. Participants reported seeking support from partners, friends, and therapists. They learned to find their inner voice and used it to fight against feelings of blame and guilt and reassure themselves that they were doing their best to be supportive:

If I was to say anything to anybody it would be, 'Own it, that it's not your fault' and just keep telling yourself that. If you have to write it on your fridge ... or get a painting on your wall, that says, 'It's not your fault,' just own it and have it somewhere, whether it's in your heart or in front of you, have that. (Robert, aged 28 years)

Participants also found their voice by connecting with others who had similar experiences. This involved speaking with the families of other victims and reading about similar cases in the newspaper. Participants were comforted to know that they were not alone. Several participated in the research project in the hope that the impact of CSA on siblings would be recognized:

That is why I agreed to do this [research] or whatever, because I don't think . . . other people know the knock-on effect is that it affects everyone in the family. That it's not just the victim. You know? That whole families are ruined because of this. (Brendan, aged 41 years) 


\section{Rescripting the Future}

All of the participants felt that their sibling's abuse altered their envisioned future. Thoughts about the future had to be adjusted to incorporate the impact of their sibling's abuse and their changed family circumstances. There were new issues stemming from the abuse experience, and while the extent of these issues tended to wax and wane over time, they were never resolved. Participants had to accept that they would be dealing with the consequences of the CSA for the rest of their lives.

Changes in family relationships meant that they felt they could no longer have the future they had imagined. Participants grieved lost relationships and important family occasions "[sibling is] still completely fucked up, she's like, her life has been stolen from her and nothing's going to change that. . . I genuinely believe this is worse than murder" (Brendan, aged 41 years). Participants also expressed a variety of fears about the future such as the continued impact of the abuse on their sister as they get older, the ongoing legal case, and fear of being confronted by the abuser or their family. Potential family crises also provoked frequent concern. Participants reported additional worry about what would happen if the family had to come together.

Participants wanted to move on from the abuse as a family. Some participants felt their sibling's inability to move on was keeping them stuck. Participants did not expect their sibling to forget about the abuse but have it "running parallel" (Rebecca, aged 49 years). They wanted to see them reclaim their lives so that they were no longer defined by their abuse experience: "it's so awful what happened to her, and honestly I do feel really bad. But I feel like saying, please you have to have a life! And you have to let us have a life now" (Claire, aged 44 years). Others felt that the drawn-out legal process kept the issues alive for them. Participants spoke about learning to accept the situation but trying to move forward. This was not peaceful acceptance but a realization that the issues related to the abuse would never fully be resolved and that recovery was a long and complicated process: "I guess it's almost as if you're like two steps forward and one step back, two steps forward and one step back, you're always progressing and moving even though you feel like you've had a setback" (Robert, aged 28 years).

Despite the difficulties they encountered and the uncertainty they faced, all participants managed to maintain a sense of hope about the future. One participant maintained hope that their family would see justice against the perpetrator. Another expressed satisfaction that her relationship with her sister was returning to a good place. Two expressed admiration at their sister's resilience and felt that while she had unresolved issues, ultimately, she would be "okay." Another felt that her sister's mental health difficulties seemed to 
be improving with therapy and was tentatively hopeful that this would continue. All participants expressed love for their sibling and commitment to stand by them and continue to be supportive:

For all of that, I really do understand why she acts the way she does, like that it has to be you know, the most traumatic thing. And especially that you were a child and your trust was taken and everything else. I do, I understand all of that, and that's kind of why I keep, you know, pushing with her. (Rebecca, aged 49 years)

\section{Discussion}

The aim of the present study was to explore adult siblings' experiences of having a sexually abused sibling. Through their narratives, participants elaborated on the enduring impact of their sibling's CSA upon their lives. Results indicated that participants experienced a combination of interpersonal and intrapersonal difficulties in their attempts to try to make sense of their siblings' abuse.

\section{Personal Impact of CSA on Siblings}

In the immediate aftermath of their sibling's disclosure, participants described feeling "disoriented and derailed," overwhelmed by anger and sadness, having difficulties concentrating, changes in sleep and appetite, and the onset of panic attacks. These reactions were similar to those noted in parents following a disclosure of CSA (Han \& Kim, 2016; Humphreys, 1995; Plummer \& Eastin, 2007). Participants highlighted their need for support in managing these issues. The importance of seeking support from others around issues related to CSA is consistently highlighted in accounts from victims (Ullman, 2003), parents (van Toledo \& Seymour, 2013), and intimate partners (Barcus, 1997; Chauncey, 1994; Jacob \& Veach, 2005). Although participants were satisfied with the informal support they received, many also saw a need for professional support and advice, particularly around what they might expect regarding the impact of CSA on their sibling, the legal process, and how best to support and communicate with their sibling.

Bowlby's (1969) model of adult sibling attachment theorized that the main purpose of the sibling relationship is to maintain the family history. A loss of this shared family history could feel threatening to the sibling bond and to date has been understudied. In their attempts to make sense of the abuse, siblings experienced feelings of grief and loss as they were forced to reevaluate their previous image of a happy childhood. Welfare (2008) found that 
adult siblings of CSA victims reported their memories of childhood had been shattered. This theme has not been described in studies on parents, so it may be unique to siblings and supports previous authors' contention that sibling relationships are unique in sharing family history and intimate family experiences (Cicirelli, 1995).

Consistent with previous research, siblings in this study struggled to develop a coherent narrative around the abuse as they were faced with vague and incomplete information (Hill, 2003; Welfare, 2008). Participants continuously discovered new information that was confusing and upsetting. Hill (2003) reported that the transition for siblings from not knowing to knowing about CSA was not clear or straightforward but an ongoing and confusing process. McElvaney, Greene, and Hogan (2012) described CSA disclosure as a continuous process that can take place over many years because victims withhold information long after the first disclosure. The findings from the present study highlight the impact of withholding information on siblings. Participants felt that not knowing limited their ability to relate to the victim and led to concerns that they might minimize the impact of the abuse. Siblings felt obligated to withhold from others out of respect for their sibling's confidentiality and feeling that it was not their secret to tell. This resulted in difficulties seeking their own social support. This difficulty was also expressed by intimate partners (Chauncey, 1994; Jacob \& Veach, 2005)

Another theme was that of rescripting the future. Participants expressed grief and loss at the changes within their families that impacted on their vision of the future. Research with intimate partners also highlights the sense of loss and mourning for the relationship they had envisioned with their partner due to the impact of CSA on their lives (Jacob \& Veach, 2005). Participants reported that there were constantly new issues stemming from the abuse and expressed a range of worries about the future. This reinforces findings from the adult victim literature that the experience of CSA is not a discreet incident but must be continuously and repeatedly confronted (Banyard \& Williams, 2007). Family Stress Theory recognizes that adapting to a crisis involves dealing with the additional "pile-up of demand" that follows the primary stressor and integrating these experiences into the new "family world view" (Patterson \& Garwick, 1994).

Participants in this study spoke of how their sibling's inability to move on impacted on their own need to move on from the abuse as a family. Previous research demonstrated the difficulties that family members can experience when victims struggle to recover from their abuse. Chauncey (1994) described intimate partners' feelings of hopelessness and impatience regarding what they felt was as a lack of improvement in victims' symptoms. Reid, Wampler, and Taylor (1996) described how husbands of victims reported feeling that 
the survivor's abuse issues became the entire focus of family life. Despite the problems, they demonstrated resilience and commitment to the recovery of their siblings and families and maintained a sense of hope for the future.

\section{Impact on the Sibling Relationship}

All participants found it difficult to speak to their sibling about the abuse and reported experiencing tension in their relationship which many described as "walking on eggshells." Interestingly, several studies of intimate partners of CSA victims used the same phrase to characterize their interactions (Barcus, 1997; Chauncey, 1994; Jacob \& Veach, 2005; Reid et al., 1996). Participants in this study described how communication could become strained and some felt that their relationship had deteriorated since the disclosure. The finding that relationships with victims can suffer as a result of the longer term impact of CSA is upheld within the existing literature. CSA is a form of relational trauma and victims themselves report experiencing a range of interpersonal problems (DiLillo, 2001). Baker et al. (2001) and Hill (2003) reported that relationships between child siblings often deteriorated following a disclosure of CSA. In both these studies, the relationships deteriorated because siblings did not believe the disclosure. The results of this study indicate that problems can occur within the sibling relationship if siblings believe the victim and want to be supportive. Parents also experience difficulties with communication and find it hard to know how best to support victims (Han \& Kim, 2016; Humphreys, 1995; Plummer \& Eastin, 2007). Parents of younger children struggle to understand and manage changes in their child's behavior, leading to a deterioration in the relationship and difficulties maintaining support for their child (Humphreys, 1995). Some participants in the present study reported feeling that their sibling could be emotionally abusive. Experiences of verbal, emotional, and physical abuse have also been reported by intimate partners of CSA victims but have not previously been reported by siblings. This has been conceptualized as a reenactment of the dynamics of CSA within the relationship (Chauncey, 1994; Jacob \& Veach, 2005; Reid et al., 1996).

The siblings in this study were affected by their sibling's CSA and were involved in supporting recovery. Despite this, they felt their own emotional experiences and supportive role went unrecognized. These findings are echoed in the literature detailing the experiences of children which describes how siblings often feel that there is no space within their families to express their feelings about the abuse (Hill, 2003).

Participants noted their commitment to their sibling's recovery but struggled to balance their own needs with the continuous need to support their 
sibling and other family members. It was also felt that the victim's expectations of support were often unclear or unrealistic and that the relationship often lacked reciprocity. These sentiments were reported by intimate partners who note the difficulties balancing conflicting needs and personal toll in sustaining ongoing support for victims (Barcus, 1997; Chauncey, 1994; Jacob \& Veach, 2005; Reid et al., 1996).

\section{Impact on Family Relationships}

Significant in this study was the transactional nature of emotions and the relationship between sibling's personal coping and other family members' distress. Participants expressed distress regarding the impact of the disclosure on their other family members. This was true for parents who were described as suffering from depression following the disclosure. Difficulties witnessing the impact of disclosure on parents has also been noted by victims of CSA (Welfare, 2008). Previous research indicated that young siblings experience feelings of anger toward nonoffending caregivers (Baker et al., 2001; Hill, 2003). As participants in this study were adults, they understood the concept of CSA and were developmentally able to take the perspective of another and understand the impact of CSA on their parents. This may represent an additional and previously unacknowledged stressor for adult siblings. This transactional nature of family coping is consistent with McCubbin and Patterson's (1983) Family Stress Model. This model posits that the impact of a stressor is determined by how the family collectively perceive and define the event. This is a reciprocal process as family members inevitably influence each other in their appraisals of stressful life events (Patterson \& Garwick, 1994). The Family Stress Model also highlights the potential for a crisis to disrupt the entire family equilibrium and change the trajectory of family functioning (Rosino, 2016). These shifts can have a significant impact on family identity and individual roles within the family (Patterson \& Garwick, 1994). All of the participants in this study felt that their normal family dynamics had been disrupted and their sense of family lost. Participants tried to take on a mediator role but were left feeling torn between different family members.

Aspects of participants' experiences are consistent with Remer and Elliott's (1988a, 1988b) theoretical model of adjustment and healing in secondary victims of CSA. Remer and Elliott describe four stages: trauma awareness, crisis and disorientation, reorganization, and integration and resolution. These authors conceptualized the range of emotional reactions and difficulties experienced by partners of CSA survivors as consistent with the trauma experienced by victims themselves. The participants in the present 
study described similar emotional reactions to those outlined by Remer and Elliott.in particular their experiences of crisis and disorientation following awareness of the trauma, their attempts to develop their own personal narratives around the abuse and renegotiating family relationships. Many participants in this study noted that the family continues to be thrown into a new state of crisis. This suggests that either the reorganization stage has not been successfully achieved or that progress through stages is not linear. Family members may revert to crises and disorientation as new information emerges or new difficulties have to be negotiated (Remer \& Ferguson, 1995). Remer and Elliott also suggest that integration and resolution occurs when the trauma becomes part of the secondary victim's personality structure and they accept the ongoing nature of the healing process. A defining element in the recovery of secondary victims is their dependence on the healing of the primary victims. For the siblings in this study, it is suggested that achieving integration and resolution may also depend on the recovery of the other family members.

\section{Strengths and Limitations}

The voices of nonabused siblings are absent from research literature. The strength of the present study lies in the focus on siblings' experiences, captured through a qualitative design that enabled siblings to share their stories in their own words, therefore expanding our understanding of siblings' experiences from the perspective of siblings themselves. This is the only study exploring the experiences of adult siblings of CSA victims. The use of an IPA methodology allowed for in-depth exploration that uncovered themes not previously identified in the literature. It builds on the knowledge base concerning the systemic impact of CSA by expanding on Remer and Ferguson's (1995) theoretical model of secondary trauma. However, as this was an exploratory, qualitative study drawing on a small sample, caution must be exercised in extrapolating the findings to other siblings of CSA victims. Participants were accessed through a therapeutic service; many declined to participate. Accessing siblings who do not present to services may present a different range of experiences. Victims of CSA may not display long-term difficulties and the experiences of sibling relationships may be different.

All participants believed their sibling's disclosureand, although they experienced difficult times with their sibling, continued to support them. It would be helpful to hear from siblings who did not believe their siblings and who do not support victims. None of the participants in this study were abused by a nuclear family member. These siblings may experience conflicted feelings toward both the victim and the perpetrator (Baker et al., 2001; Hill, 2003). 
Stroud (1999) found that the closer the biological relationship to the perpetrator, the less supportive siblings were. All victims were females; male victims have reported receiving less family support after a disclosure of CSA than females (Stroud, 1999). All of the participants in this study, and their families, did not learn about their sibling's CSA until adulthood. Experiences, such as rewriting the past, would presumably be different for siblings who have known since childhood of their sibling's abuse.

Inclusion of multiple siblings from the same family is a strength because this provides different perspectives within the same family. Finally, the sample was not culturally diverse, meaning it is not possible to examine the degree to which cultural norms might influence sibling experiences. Ireland remains a predominantly catholic country and the church has had an influence on Irish culture.

\section{Implications for Research and Practice}

Participants in this study reported commitment to supporting their victim sibling but faced a number of barriers in providing such support. Barriers were feeling unprepared about what to expect, lacking knowledge in how best to support the victim, and trouble balancing personal needs. The importance of psychoeducation for family members following disclosure has been highlighted in the literature. Miller and Sutherland (1999) and van Toledo and Seymour (2013) emphasized normalizing initial emotional reactions, overcoming feelings of guilt or self-doubt, and informing about the long-term nature of recovery and how relational dynamics can play out for abuse victims. Joint therapy sessions may help address difficulties that emerge in the relationship and allow both victims and siblings to feel acknowledged and understood in a safe and containing environment (Miller $\&$ Sutherland, 1999). Siblings frequently mediate family conflict. Therefore, including them in family therapy may improve effective family communication and develop more consistent approaches to supporting the victim.

Participants in this study learned about the importance of self-care and seeking support after experiencing significant difficulties. Professionals working with siblings engaged in supporting CSA victims need to help them to recognize their personal limits and encourage self-care. This may help prevent siblings from developing mental health difficulties and caregiver burnout. Siblings may need to seek individual support. It may also be necessary to help siblings to set clear limits about the unacceptability of any abusive and violent behavior directed toward them by their victim sibling (Miller \& Sutherland, 1999). Sibling support groups may be useful in providing an opportunity to share their experiences and provide a sense of understanding of their unique position. 


\section{Conclusion}

This study highlights the impact of having a sibling who has experienced CSA and shows that siblings are vulnerable to experiencing personal difficulties in the aftermath of the disclosure. The results from this study parallel findings from intimate partner and parental research that the impact of CSA extends beyond the primary victim and can also pervade the lives of those close to survivors resulting in secondary victims (Remer \& Ferguson, 1995). Although there are many parallels between the experiences of siblings, parents, and intimate partners, the present study also highlighted a number of issues that appear unique to siblings. Specifically, the need to reevaluate childhood memories. Future research might use the framework of the present study to investigate, in depth, the themes identified here.

The role of family support for the recovery of CSA survivors has been illustrated for both adults and children; however, the role of sibling support has been overlooked. This study highlights that siblings can potentially represent a source of valuable support. The participants in this study also further contributed to the current understanding of the difficulties which can arise in supporting a family member in their recovery from CSA.

This article provides a voice to a group of individuals who have remained silenced. Knowledge gleaned from sibling experiences will benefit siblings and may aid in our understanding of family dynamics after CSA disclosures.

\section{Declaration of Conflicting Interests}

The author(s) declared no potential conflicts of interest with respect to the research, authorship, and/or publication of this article.

\section{Funding}

The author(s) received no financial support for the research, authorship, and/or publication of this article.

\section{References}

Baker, J. N., Tanis, H. J., \& Rice, J. B. (2001). Including siblings in the treatment of child sexual abuse. Journal of Child Sexual Abuse: Research, Treatment, \& Program Innovations for Victims, Survivors, \& Offenders, 10(3), 1-16. doi:10.1300/J070v10n03 01

Banyard, V. L., \& Williams, L. M. (2007). Women's voices on recovery: A multimethod study of the complexity of recovery from child sexual abuse. Child Abuse \& Neglect, 31, 275-290. doi:10.1016/j.chiabu.2006.02.016

Barcus, R. (1997). Partners of survivors of abuse: A men's therapy group. Psychotherapy: Theory, Research, Practice, Training, 34, 316-323. doi:10.1037/ h0087830 
Bowlby, J. (1969) Attachment and loss, Vol. 1: Attachment. New York, NY: Basic Books.

Chauncey, S. (1994). Emotional concerns and treatment of male partners of female sexual abuse survivors. Social Work, 39, 669-676.

Cicirelli, V. G. (1989). Feelings of attachment to siblings and well-being in later life. Psychology and Aging, 4, 211-216. doi:10.1037/0882-7974.4.2.211

Cicirelli, V. G. (1995). Sibling relationships across the life span. New York, NY: Plenum Press. doi:10.1007/978-1-4757-6509-0

Cox, M. J. (2010). Family systems and sibling relationships. Child Development Perspectives, 4, 95-96. doi:10.1111/j.1750-8606.2010.00124.x

Cyr, M., Frappier, J., Hébert, M., Tourigny, M., McDuff, P., \& Turcotte, M. (2016). Psychological and physical health of nonoffending parents after disclosure of sexual abuse of their child. Journal of Child Sexual Abuse: Research, Treatment, \& Program Innovations for Victims, Survivors, \& Offenders, 25, 757-776. doi:1 $0.1080 / 10538712.2016 .122872$

Davies, M. G. (1995). Parental distress and ability to cope following disclosure of extrafamilial sexual abuse. Child Abuse \& Neglect, 19, 399-408. doi:10.1016/01452134(95)00010-6

DiLillo, D. (2001). Interpersonal functioning among women reporting a history of childhood sexual abuse: Empirical findings and methodological issues. Clinical Psychology Review, 21, 553-576. doi:10.1016/S0272-7358(99)00072-0

Elliott, A. N., \& Carnes, C. N. (2001). Reactions of nonoffending parents to the sexual abuse of their child: A review of the literature. Child Maltreatment, 6, 314-331. doi: $10.1177 / 1077559501006004005$

Gass, K., Jenkins, J., \& Dunn, J. (2007). Are sibling relationships protective? A longitudinal study. Journal of Child Psychology and Psychiatry, 48, 167-175. doi:10.1111/j.1469-7610.2006.01699.x

Han, S., \& Kim, J. (2016). Perceived needs for support program for family with child sexual abuse victim in South Korea: Focus group interview with therapists and mothers. Journal of Child Sexual Abuse: Research, Treatment, \& Program Innovations for Victims, Survivors, \& Offenders, 25, 738-756. doi:10.1080/1053 8712.2016.1221489

Hill, A. (2003). Issues facing brothers of sexually abused children: Implications for professional practice. Child \& Family Social Work, 8, 281-290. doi:10.1046/ j.1365-2206.2003.00291.x

Humphreys, C. (1995). Counselling and support issues for mothers and fathers of sexually abused children. Australian Social Work, 48(4), 13-20. doi:10.1080/ 03124079508412496

Jacob, C. M. A., \& Veach, P. M. (2005). Intrapersonal and familial effects of child sexual abuse on female partners of male survivors. Journal of Counseling Psychology, 52, 284-297.

Kia-Keating, M., Sorsoli, L., \& Grossman, F. K. (2010). Relational challenges and recovery processes in male survivors of childhood sexual abuse. Journal of Interpersonal Violence, 25, 666-683. doi:10.1177/0886260509334411 
Maniglio, R. (2009). The impact of child sexual abuse on health: A systematic review of reviews. Clinical Psychology Review, 29, 647-657. doi:10.1016/j. cpr.2009.08.003

McCubbin, H. I., \& Patterson, J. M. (1983). The family stress process: The double ABCX model of adjustment and adaptation. Marriage \& Family Review, 6(1-2), 7-37. doi:10.1300/J002v06n01_02

McElvaney, R. (2015). Disclosure of child sexual abuse: Delays, non-disclosure and partial disclosure. What the research tells us and implications for practice. Child Abuse Review, 24, 159-169. doi:10.1002/car.2280

McElvaney, R., Greene, S., \& Hogan, D. (2012). Containing the secret of child sexual abuse. Journal of Interpersonal Violence, 27, 1155-1175. doi:10.1177/0886260511424503

Milevsky, A. (2005). Compensatory patterns of sibling support in emerging adulthood: Variations in loneliness, self-esteem, depression and life satisfaction. Journal of Social and Personal Relationships, 22, 743-755. doi:10.1177/0265407505056447

Miller, R. M., \& Sutherland, K. J. (1999). Partners in healing: Systemic therapy with surivors of sexual abuse and their partners. Journal of Family Studies, 5, 113120. doi.org/10.5172/jfs.5.1.97

Patterson, J. M., \& Garwick, A. W. (1994). Levels of meaning in family stress theory. Family Process, 33, 287-304.

Plummer, C. A., \& Eastin, J. (2007). The effect of child sexual abuse allegations/ investigations on the mother/child relationship. Violence Against Women, 13, 1053-1071. doi:10.1177/1077801207305931

Pogue, J. K., Theimer, K., Pittenger, S. L., Schreier, A., Meidlinger, K., Biles, B., . . Hansen, D. J. (2015, November). Recognizing the impact of familial distress: Improving mental health services for sexually abused youth by including caregivers and non-abused siblings. Poster presented at the 49th Annual Convention of the Association for Behavioral and Cognitive Therapies, Chicago, IL.

Reid, K. S., Wampler, R. S., \& Taylor, D. K. (1996). The "alienated" partner: Responses to traditional therapies for adult sex abuse survivors. Journal of Marital and Family Therapy, 22, 443-453. doi:10.1111/j.1752-0606.1996. tb00219.x

Remer, R., \& Elliott, J. E. (1988a). Characteristics of secondary victims of sexual assault. International Journal of Family Psychiatry, 9, 373-387.

Remer, R., \& Elliott, J. E. (1988b). Management of secondary victims of sexual assault. International Journal of Family Psychiatry, 9, 389-401.

Remer, R., \& Ferguson, R. A. (1995). Becoming a secondary survivor of sexual assault. Journal of Counseling \& Development, 73, 407-413. doi:10.1002/ j.1556-6676.1995.tb01773.x

Rosino, M. (2016). ABC-X model of family stress and coping. In The Wiley Blackwell encyclopedia of family studies. Oxford, UK: Wiley-Blackwell. doi:10.1002/ 9781119085621.wbefs313

Schreier, A., Pogue, J. K., \& Hansen, D. J. (2017). Impact of child sexual abuse on non-abused siblings: A review with implications for research and practice. Aggression and Violent Behavior, 34, 254-262. doi:10.1016/j.avb.2016.11.011 
Smith, J. A., Flowers, P., \& Larkin, M. (2009). Interpretative phenomenological analysis: Theory, method and research. London, England: SAGE.

Stroud, D. D. (1999). Familial support as perceived by adult victims of childhood sexual abuse. Sexual Abuse: Journal of Research and Treatment, 11, 159-175. doi:10.1007/BF02658845

Tavkar, P., \& Hansen, D. J. (2011). Interventions for families victimized by child sexual abuse: Clinical issues and approaches for child advocacy centerbased services. Aggression and Violent Behavior, 16, 188-199. doi:10.1016/j. avb.2011.02.005

Ullman, S. E. (2003). Social reactions to child sexual abuse disclosures: A critical review. Journal of Child Sexual Abuse: Research, Treatment, \& Program Innovations for Victims, Survivors, \& Offenders, 12, 89-121. doi:10.1300/ J070v12n01 05

van Toledo, A., \& Seymour, F. (2013). Interventions for caregivers of children who disclose sexual abuse: A review. Clinical Psychology Review, 33, 772-781. doi:10.1016/j.cpr.2013.05.006

Walsh, K., Fortier, M. A., \& DiLillo, D. (2010). Adult coping with childhood sexual abuse: A theoretical and empirical review. Aggression and Violent Behavior, 15, 1-13. doi:10.1016/j.avb.2009.06.009

Welfare, A. (2008). How qualitative research can inform clinical interventions in families recovering from sibling sexual abuse. Australian \& New Zealand Journal of Family Therapy, 29, 139-147. doi:10.1375/anft.29.3.139

\section{Author Biographies}

Elaine Crabtree is a student of the Doctoral Program in Clinical Psychology, Trinity College Dublin. Her research interests include family trauma and the systemic impact of child abuse.

Charlotte Wilson is an assistant professor in Clinical Psychology, Trinity College Dublin. Her research focuses on Children's Mental Health, parenting, and the experiences and voices of service users in all specialties. She is interested in pedagogical research within applied psychology and psychotherapy.

Rosaleen McElvaney is a clinical psychologist who has worked in the public health services in Ireland for many years, mostly in services for children or adults who have experienced sexual abuse. She has served on the Boards of Crime Victims Helpline, the National Board for Safeguarding Children in the Catholic Church in Ireland, and One in Four. She is a past president of the Psychological Society of Ireland and currently chair of the European Federation of Psychologists' Associations (EFPA) Specialist European Awarding Committee for psychologists specializing in psychotherapy. She has a particular interest in professional training and have had the opportunity to work on training programs for clinical psychologists, counseling psychologists, social care workers, and psychotherapists. She is currently a board member of the Nursing and Midwifery Board of Ireland (NMBI). 